\title{
Burnout syndrome in the banking sector of Bosnia and Herzegovina
}

\author{
Zana Tafi',2*, Alisa Smajović3, Vanesa Škrijelj4, Ramajana Temimović1, Tamara Jovović Sadiković5, \\ Samra Poturak', Selma Karakaš-Osmanović', Sanja Brekalo Lazarevićc
}

${ }^{1}$ Institute of Occupational Medicine, Sarajevo, Bosnia and Herzegovina, ${ }^{2}$ Departmend of Propedutics, Sarajevo School of Medicine, University of Sarajevo School of Science and Technology, Sarajevo, Bosnia and Herzegovina, ${ }^{3}$ Department of Pharmaceutical Informatics and Pharmacoeconomics, Faculty of Pharmacy, University of Sarajevo, Sarajevo, Bosnia and Herzegovina, "Department of Pediatrics, General hospital "Abdulah Nakaš," Sarajevo, Bosnia and Herzegovina, ${ }^{5}$ Department of Dermatology, Sarajevo School of Medicine, University of Sarajevo School of Science and Technology, Sarajevo, Bosnia and Herzegovina, ${ }^{6}$ Occupation Medicine, Public Health Center, "Dr. Mustafa Šehović" Tuzla, Bosnia and Herzegovina

\section{ABSTRACT}

Introduction: Burnout syndrome in some European countries is recognized as an occupational disease. In the past time, it has been identified predominantly in the service sectors such as healthcare, social services, mental health and education, but later it started to be predominant in other occupations with high job requirements and time pressure. The aim of this study was to assess the presence of burnout at work among the bank employees of Sarajevo Canton, Bosnia and Herzegovina.

Methods: A cross-sectional study was conducted in banks $(n=6)$ located in Sarajevo Canton, Bosnia and Herzegovina, between January and April 2018. Employees filled out an anonymous questionnaire, after their written informed consent had been obtained. The study included employees regardless of their job positions and job seniority.

Results: The total number of surveyed employees was 260. There are not statistically significant gender differences $(p=0.854, p<0.05)$ compared to the total Maslach Burnout Inventory (MBI) score. Statistically significant differences in relation to the total MBI score were observed in the examinees who have been working in the banking sector between 15 and 20 years $(p=0.04 ; p<0.05)$ and examinees working temporarily $<2 \mathrm{~h} /$ week $(p=0.016 ; p<0.05)$, that is, more than $8 \mathrm{~h} /$ week $(p=0.015 ; p<0.05)$. Mid value and standard deviation of the score in the subscale of emotional exhaustion (EE) is $26.26 \pm 11.15$, which shows that one third of the examinees are in high risk of EE.

Conclusion: We can conclude that less than one third of examinees are in high risk of burnout syndrome.

Keywords: Burnout syndrome; banking sector; maslach burnout syndrome; job satisfaction; emotional exhaustion; depersonalization

\section{INTRODUCTION}

In recent decades, the economy has been changing as a result of global economy crisis. The biggest changes are in the way the banks have been organized which affected the lives of the employees (1). The banking sector is an area in which there are changes in direction of mass layoffs, acquisitions and crashes, digitalization, outsourcing, business re-engineering with the decrease in the levels of hierarchy, job insecurity, increasing competition due to the entrance of more private banks (corporate) (2).

As the technology applied in banking sector became more sophisticated, bank employees gained more qualifications

*Corresponding author: Zana Tafi, Institute of Occupational Medicine, Bulevar Meše Selimovića 2, Sarajevo - 71000, Bosnia and Herzegovina; Departmend of Propedutics, Sarajevo School of Medicine, University of Sarajevo School of Science and Technology, Sarajevo - 71000, Bosnia and Herzegovina, Bosnia and Herzegovina. E-mail: zana.tafi@ssst.edu.ba

Submitted: 20 December 2020/Accepted: 18 November 2021 and became "expert sellers," which did not only affect the way of being a bank employee, this affected their health and increased the frequency of occupational diseases (3). As a result of increasing pressure, tension and stress in the banking sector the changes in the bank environment affected also the health of its workers (1). Burnout at work is an individual response to work pressure and occupational stress (4). It is a syndrome characterized by emotional exhaustion (EE), depersonalization (DP) (negative, indifferent, distant, cynical attitudes, and impersonal feelings toward others) and reduced personal accomplishment (feeling of successful achievement in one's work). The Maslach Burnout Inventory (MBI) is a reference instrument for measuring burnout in professional occupations (5). According to the World Health Organization, work-related stress is the response people may have when presented with work demands and pressures that are not matched to their knowledge and abilities and which challenge their ability to cope (6). Hence, the MBI serves as the gold standard to assess burnout, which effectively means that burnout is what the MBI measures (7). 
Burnout syndrome is in some European countries recognized as an occupational disease. Burnout syndrome has been earlier identified predominantly in the service sectors such as healthcare, social services, mental health and education, but later it started to be predominant in other occupations with high job requirements and time pressure (e.g., managers) like bank employees $(8,9)$. According to the European Foundation for the Improvement of Living and Working Conditions (Eurofound) stress is one of the major occupational problems in banking sector (10). When the bank employees are dealing with costumers, they need to stay focused, pay attention to their appearance and be capable to overcome current and future challenges. For those reasons bank employees are vulnerable group at a highlevel of risk of burnout at work because of excessive work demands, role conflicts, responsibility to people, complex relationships with customers, and increased pressure in how much time they need to solve their tasks $(11,12)$. According to the European Observatory of Working Life the main risk factors of occupational stress, known as job stressors, are heavy workload, long working hours, the lack of control and autonomy at work, poor relationships with colleagues, poor support at work as well as high job demands and low job control (13).

A systematic review of prospective studies showed physical consequences of burnout at work. The most common physical outcomes were cardiovascular diseases, metabolic syndrome, diabetes mellitus type 2, hypertension, high triglycerides, low HDL cholesterol, and high LDL cholesterol $(11,12)$.

The relationships between occupational stress and burnout at work have been analyzed in number of different occupations. However, these relationships have not been tested with Bosnian and Herzegovina bank employees. Based on that fact main objective of the present study is focused on male and female employees in the Bosnian and Herzegovina banking sector. While this study specifically focuses on the data collected in the Sarajevo Canton, some of the findings are expected to be applicable to wider environment, especially to banks and other financial institutions in the emerging economy countries that face similar challenges.

A study of such nature was helpful to understand the problem of stress level and its associated factors. With this background, the aim of this study was to assess the presence of burnout at work among the bank employees of Bosnia and Hercegovina.

A review of the literature did not record any similar research, conducted on the topic of burnout at work in Bosnia and Herzegovina, thus the importance of the results is that much more significant.

\section{METHODS}

A cross-sectional study was conducted in 6 banks located in Sarajevo Canton, Bosnia and Herzegovina, between January and April 2018. Employees filled out an anonymous questionnaire, after their written informed consent had been obtained. The study included all employees regardless of their job positions and job seniority. The study included 260 randomly chosen banking sector employees in all bank departments in the Sarajevo Canton.
During the study period, we collected 312 questionnaires out of which 287 have been completed. After subsequent elimination based on inclusion and exclusion criteria, we included 260 participants in our analysis, out of whom $57(21.9 \%)$ were male individuals and 203 (78.1\%) were female individuals. Inclusion criteria were that the chosen individuals were full-time bank employees who maintained regular office hours for at least 3 months in banks and were between 18 and 65 years of age. Pregnant women, female employees who have a baby younger than 6 months and employees with any previously diagnosed psychiatric disorders could not have participated in the study (14).

Demographic factors included age, gender, qualifications, bank type, job rank, type of job contract (permanent vs. temporary) and working hours, length of employment at the bank, whether they had children, their smoking habits, alcohol consumption and previous or present consumption of antidepressants or sedatives (drugs). Marital status was categorized as "single/widowed/divorced/separated" and "married/cohabitating." Education was categorized as "junior college or lower," "college," and "graduate or higher." Job seniority was categorized as "leading bank employee" or "ordinary bank employee" based on responses to the question "Are you in a leading bank position or an ordinary bank employee? "Weekly working hours were categorized as " $\leq 40$ h," and " $>40$ h," a categorization derived from the current standard work system of $8 \mathrm{~h}$ per day.

MBI is made up of three parts: a sense of EE (9 claims), DP (5 claims) and Personal job satisfaction (8 claims), so the total number of claims were 22 . For each statement on the Likert scale of 7 degrees it is necessary to determine the degree of agreement, so each of the claims can be scored as: 0-never; 1 - several times per year or less; 2 - ounce per month or less; 3 - several times per month; 4 - ounce per week; 5 - several times per week and 6 - every day, so the maximum total MBI score is 132 . Interpretation of data is made according to Thorsen et al. (Table 1) (13).

Statistical analysis of the data was done using IBM SPSS Statistics Version 24 (15). Level of significance was set on $p<0.05$.

The study protocol was approved by the Ethical committee of the Institute of occupational medicine of the Sarajevo Canton.

TABLE 1. Maslach Burnout inventory

\begin{tabular}{llc}
\hline Subscale & Category & Value \\
\hline EE & High & $\geq 27$ \\
& Moderate & $19-26$ \\
& Low & $0-18$ \\
DP & High & $>10$ \\
& Moderate & $6-9$ \\
& Low & $0-5$ \\
Personal Job Satisfaction (PA) & High & $0-33$ \\
& Moderate & $34-39$ \\
& Low & $\geq 40$ \\
\hline
\end{tabular}

EE: Emotional exhaustion, DP: Depersonalization, PA: Personal achievement 


\section{RESULTS}

The total number of employees surveyed were 260 , out of whom 57 were men $(21.9 \%)$ and 203 were women $(78.1 \%)$. Average results of MBI analysis are shown in Table 2.

The reliability of the MBI scale was tested using Cronbach's alpha coefficient, and the results were as follows:

1. For the EE subscale, Cronbach's alpha had a value of 0.697

2. For the DP subscale, the effort-induced discomfort Cronbach's alpha had a value of 0.756

3. For the Personal job satisfaction subscale Cronbach's alpha had a value of 0.866

According to the literature (16) the acceptable value of Cronbach's alpha is at least 0.7 , from which it can be concluded that the obtained coefficient values for the three subscales are acceptable.

Exploratory analysis was performed using the Principal Component Analysis extraction method and the Varimax rotation method. The results showed that the claims are grouped in 5 main factors (Table 3) that explain $61.17 \%$ of the variance.

The multiple regression analysis examines whether the total MBI score is influenced by gender, qualifications, length of service, and overtime work. The results showed no statistically significant differences between men and women

TABLE 2. Average results of MBI analysis

\begin{tabular}{lc}
\hline Subscale & Mean \pm Standard deviation \\
\hline Subscale EE & $26.26 \pm 11.15$ \\
Subscale DP & $7.97 \pm 6.56$ \\
Subscale PA & $34.25 \pm 9.48$ \\
Total score & $68.52 \pm 16.24$ \\
\hline
\end{tabular}

MBI: Maslach Burnout inventory, EE: Emotional exhaustion, DP: Depersonalization, PA: Personal achievement
( $p=0.854 ; p<0.05)$, also no statistically significant difference in relation to the qualifications which the participants had, as well as in relation to the length of service, except for respondents who work in the banking sector between 15 and 20 years $(p=0.04 ; p<0.05)$. However, there are statistically significant differences in whether the respondent works overtime or not (Table 4).

\section{DISCUSSION}

It is a well-known fact that works in the banking sector is highly stressful which facilitates the development of the burnout symptoms at work. It is even bigger problem that the employees often do not recognize the symptoms which in time leads to the increase of their intensity and further development of hardships in everyday life, whether of physical or psychological nature.

The main goal of this research was to assess the presence of burnout at work among the bank employees of Bosnia and Herzegovina using MBI.

A total number of surveyed employees in the banking sector was 260, out of whom 57 were male $(21.9 \%)$ and 203 female $(78.1 \%)$ employees. However, according to the results there are no statistically significant gender difference ( $p=0.854)$ compared to the total MBI score, which correlates to some findings in the literature where it was shown that the component of $\mathrm{EE}$ is a bit more observed in female employees, whereas DP prevailed with male employees, but in total score there were no significant gender differences (17). Similiar results could also be seen in the Horvat et al. (2016) study where it was proven that there is no statistically significant difference in the work burnout levels between women and men. On the other hand there are studies showing opposite results (18). One of them is a study by Cakınberk (2011) which shows that there are

TABLE 3. Factor analysis

\begin{tabular}{|c|c|c|c|c|}
\hline $\begin{array}{l}\text { Factor } 1 \text { - Emotional } \\
\text { Exhaustion }\end{array}$ & Factor 2 - Job satisfaction & $\begin{array}{l}\text { Factor } 3 \\
\text { - Depersonalization }\end{array}$ & Factor 4 - Driving force & $\begin{array}{l}\text { Factor } 5 \text { - Financial } \\
\text { satisfaction }\end{array}$ \\
\hline $\begin{array}{l}\text { 1. I feel it is too stressful to } \\
\text { work in direct contact with } \\
\text { people }\end{array}$ & $\begin{array}{l}\text { 15. I am very effective } \\
\text { in solving my clients' } \\
\text { problems }\end{array}$ & $\begin{array}{l}\text { 10. In fact, I don't care what } \\
\text { happens to my clients }\end{array}$ & $\begin{array}{l}\text { 6. I am satisfied with } \\
\text { the quality of my } \\
\text { sleep }\end{array}$ & $\begin{array}{l}\text { 3. I am satisfied with the } \\
\text { financial compensation for } \\
\text { the work }\end{array}$ \\
\hline $\begin{array}{l}\text { 2. My job makes me } \\
\text { frustrated }\end{array}$ & $\begin{array}{l}\text { 16. I feel that I have a } \\
\text { positive impact on other } \\
\text { people's lives through } \\
\text { my work }\end{array}$ & $\begin{array}{l}\text { 11. I feel that I treat some } \\
\text { clients as if they were } \\
\text { impersonal objects }\end{array}$ & $\begin{array}{l}\text { 18. I have done many } \\
\text { things "worth } \\
\text { the effort" in this } \\
\text { business }\end{array}$ & \\
\hline $\begin{array}{l}\text { 4. I feel emotionally } \\
\text { exhausted after work }\end{array}$ & $\begin{array}{l}\text { 17. I feel very happy to have } \\
\text { close contact with my } \\
\text { clients }\end{array}$ & $\begin{array}{l}\text { 12. I have become } \\
\text { insensitive to other } \\
\text { people since doing } \\
\text { this job }\end{array}$ & 19. I feel full of energy & \\
\hline $\begin{array}{l}\text { 5. I feel tired at the thought } \\
\text { of having to go to work }\end{array}$ & $\begin{array}{l}\text { 20. I can easily understand } \\
\text { what my clients are } \\
\text { feeling }\end{array}$ & $\begin{array}{l}\text { 13. Working with people all } \\
\text { day is a tremendous } \\
\text { strain for me }\end{array}$ & & \\
\hline $\begin{array}{l}\text { 7. I recently lost a lot } \\
\text { of sleep because of } \\
\text { worrying }\end{array}$ & $\begin{array}{l}\text { 21. I take great care of my } \\
\text { clients' problems }\end{array}$ & \multirow{2}{*}{$\begin{array}{l}\text { 14. I get the impression } \\
\text { that my clients hold me } \\
\text { responsible for some of } \\
\text { their problems }\end{array}$} & & \\
\hline $\begin{array}{l}\text { 8. I am exposed to } \\
\text { organizational injustice }\end{array}$ & $\begin{array}{l}\text { 22. I'm very easily able } \\
\text { to create a relaxed } \\
\text { atmosphere with my } \\
\text { clients }\end{array}$ & & & \\
\hline $\begin{array}{l}\text { 9. I feel like I'm working too } \\
\text { hard in my workplace }\end{array}$ & & & & \\
\hline
\end{tabular}


TABLE 4. Factor Fills for the $22 \mathrm{MBI}$ questions

\begin{tabular}{|c|c|c|c|c|c|}
\hline Emotional exhaustion & $\begin{array}{l}\text { Emotional } \\
\text { exhaustion }\end{array}$ & $\begin{array}{c}\text { Job } \\
\text { satisfaction }\end{array}$ & Depersonalization & $\begin{array}{l}\text { Driving } \\
\text { force }\end{array}$ & $\begin{array}{l}\text { Financial } \\
\text { satisfaction }\end{array}$ \\
\hline 1. I feel it is too stressful to work in direct contact with people & 0.675 & -0.039 & 0.019 & 0.092 & 0.112 \\
\hline 2. My job makes me frustrated & 0.827 & -0.108 & 0.077 & 0.007 & -0.056 \\
\hline 4. I feel emotionally exhausted after work & -0.153 & 0.012 & -0.103 & 0.336 & 0.717 \\
\hline 5. I feel tired at the thought of having to go to work & 0.819 & 0.017 & 0.069 & -0.089 & 0.028 \\
\hline 7. I recently lost a lot of sleep because of worrying & 0.673 & -0.019 & 0.070 & -0.179 & -0.023 \\
\hline 8. I am exposed to organizational injustice & 0.647 & -0.023 & 0.030 & -0.053 & -0.066 \\
\hline 9. I feel like l'm working too hard in my workplace & 0.784 & 0.007 & 0.032 & -0.137 & -0.063 \\
\hline \multicolumn{6}{|l|}{ Job satisfaction } \\
\hline 15. I am very effective in solving my clients' problems & -0.035 & 0.685 & -0.004 & 0.054 & -0.076 \\
\hline $\begin{array}{l}\text { 16. I feel that I have a positive impact on other people's lives } \\
\text { through my work }\end{array}$ & -0.074 & 0.666 & 0.033 & 0.340 & -0.132 \\
\hline 17. I feel very happy to have close contact with my clients & -0.110 & 0.630 & 0.020 & 0.431 & -0.101 \\
\hline 20. I can easily understand what my clients are feeling & -0.020 & 0.855 & 0.037 & -0.049 & 0.163 \\
\hline 21. I take great care of my clients' problems & 0.028 & 0.859 & 0.008 & -0.056 & 0.111 \\
\hline $\begin{array}{l}\text { 22. I'm very easily able to create a relaxed atmosphere with } \\
\text { my clients }\end{array}$ & -0.020 & 0.839 & 0.009 & 0.068 & 0.026 \\
\hline \multicolumn{6}{|l|}{ Depersonalization } \\
\hline 10. In fact, I don't care what happens to my clients & 0.154 & 0.058 & 0.604 & -0.093 & 0.488 \\
\hline $\begin{array}{l}\text { 11. I feel that I treat some clients as if they were impersonal } \\
\text { objects }\end{array}$ & -0.034 & 0.007 & 0.803 & -0.065 & 0.113 \\
\hline $\begin{array}{l}\text { 12. I have become insensitive to other people since doing } \\
\text { this job }\end{array}$ & 0.008 & -0.014 & 0.793 & -0.019 & 0.076 \\
\hline 13. Working with people all day is a tremendous strain for me & 0.177 & -0.004 & 0.671 & 0.214 & -0.347 \\
\hline $\begin{array}{l}\text { 14. I get the impression that my clients hold me responsible } \\
\text { for some of their problems }\end{array}$ & 0.124 & 0.043 & 0.673 & 0.023 & -0.218 \\
\hline \multicolumn{6}{|l|}{ Driving force } \\
\hline 10. In fact, I don't care what happens to my clients & -0.033 & -0.035 & 0.040 & 0.646 & 0.239 \\
\hline $\begin{array}{l}\text { 11. I feel that I treat some clients as if they were impersonal } \\
\text { objects }\end{array}$ & -0.061 & 0.485 & -0.033 & 0.576 & -0.117 \\
\hline $\begin{array}{l}\text { 12. I have become insensitive to other people since doing } \\
\text { this job }\end{array}$ & -0.234 & 0.402 & -0.016 & 0.592 & 0.082 \\
\hline \multicolumn{6}{|l|}{ Financial satisfaction } \\
\hline 3. I am satisfied with the financial compensation for the work & -0.153 & 0.012 & -0.103 & 0.336 & 0.717 \\
\hline
\end{tabular}
MBI: Maslach Burnout inventory

differences in burnout levels of bank employees, its terms of variables such as gender (19).

Gidou et al. (2020) showed that there is difference between genders and that female employees have higher burnout stress (20). Gender difference in burnout is also supported by study from Al-Kahtani and Allam which showed that men have higher levels of job burnout compared to women (21).

If we behold working experience as a factor, statistically significant differences in relation to the total MBI score were observed in participants who have been working in the banking sector between 15 and 20 years $(p=0.04)$. Individuals who have been working in the banking sector between 10 and 15 years are middle-aged with enough knowledge and experience in their professional career and ambition. On the other hand, they are requested to work harder and have higher responsibility than younger employees, wich could contribute to higher job bunout. Results of the University Clinical Center of Republic of Srpska study also show bigger EE in older doctors $(p=0.030)(22)$.

Research in the correlation between the workings years and burnout syndrome has been conducted in the Horvat et al. study where the working years of the examinees ranged between 1 and 36, but the results showed that there was no correlation between the two parameters, that is, that the number of the working years does not significantly affect the burnout syndrome (18).

In this study, the results show that participants who work temporarily $<2$ h overtime/week, and those who work more than 8 h overtime/week $(p=0.015)$ show statistically significant differences in MBI score $(p=0.015)$. Study Hino et al. (2019) among Japanese white-collar workers, showed the effect of changes in overtime work hours on depressive symptoms. Overtime work hours were defined as the total working hours in excession of $160 \mathrm{~h}$ during 1 month. Their results showed that the workers with decreased overtime work ( $44 \mathrm{~h}$ or less) had the lowest average depressive symptoms score (9.56) and statistically significant differences were observed compared to the stable medium overtime work ( 45 do $79 \mathrm{~h}$ ) and increased overtime groups ( $80 \mathrm{~h}$ or more) (23).

Examining the effects of overtime work on subjective social status and sense of social inclusion in the Chinese context, findings suggest that workers who had long work hours (more than $40 \mathrm{~h} /$ week) are more likely to underestimate their social class perception and feel less social inclusion. 
Secondly, many findings have indicated that the overtime work in developing countries, such as the United States and Japan is more widespread, and employees suffer from more time-related stress, which leads to more serious psychological and sociological implications (24).

As it can been seen in the Table 4, no significant differences have been spotted in the burnout levels in relation to the education degrees of the examinees. Cakınberk study (2011) examined the correlation between the professional burnout and life satisfaction and it has proved that the higher EE and DP levels, as well as lower Personal achievement (PA) level, have been connected with the education degrees, therefore this factor should not be neglected and it needs to be paid a special attention to in the future researches of larger number of participants (19)

The aim of the factor analysis was to reduce a number of data, that is, to group the claims according to the factors influencing the data variations and determine whether there is a correlation between 22 facts within MBI. Explorative analysis was conducted with the Principal Component Analysis extraction method and Varimax rotation method. Results have shown that the claims grouped in 5 factors (Table 2) which explain $61.17 \%$ variants. First three factors were defined as EE (Factor 1), job fulfillment (Factor 2) and DP (Factor 3), whereas fourth and fifth factors were defined as the driving force (Factor 4 ) and financial satisfaction (Factor 5). Factor 1 defines the biggest number of claims, seven of them, whereas Factor 5 defines the lowest number of them, only one.

Based on the factor load it is indicative that the main factors contributing to $\mathrm{EE}$ of the participants are their feeling frustrated about their job - Claim 2 (0.827), tired while thinking about going to work - Claim 5 (0.819) and feeling that they are working too hard - Claim 9 (0.784). The biggest load in DP is the feeling that clients are being treated as impersonal objects - Claim 11 (0.803), that is, they feel insensitive to other people - Claim 12 (0.793). Positive claims that "they are effectively taking care of their clients' problems" - Claim 21 (0.859), that is, "very easily understand their clients' feelings" - Claim 20 (0.855) and "I can easily create relaxed atmosphere with my clients" - Claim 22 (0.839), have largely contributed to the personal feeling of job satisfaction. On the other hand, financial satisfaction represents criteria important in the appearance of the burnout syndrome - Claim 3 (0.717).

According to the estimated risk of burnout at work appearing, compared to subscales, we differ high, mid and low risk. As it can be seen from Table 5 and Table 2, 47.31\% of participants have high EE with average value of 26.26, $44.23 \%$ of participants have low DP with average value of 7.97, and $42.69 \%$ of participants have high PA with average value of 34.25 .

These results are consistent with the study carried out by Amigo et al. (25). The study included more than 1300 employees in the banking sector and results showed high risk of burnout, with the EE dimension mostly contributing to these results, some $63.16 \%$ of the examinees had high risk values, $60.92 \%$ had high DP risk, whereas $28.41 \%$ of examinees had low PA level. In order for the burnout to
TABLE 5. Number of participants among the subscales

\begin{tabular}{llc}
\hline Subscale & Category & $\begin{array}{c}\text { Number of } \\
\text { participants (\%) }\end{array}$ \\
\hline EE & High & $123(47.31)$ \\
& Moderate & $76(29.23)$ \\
& Low & $61(23.46)$ \\
DP & High & $91(35)$ \\
& Moderate & $54(20.77)$ \\
Personal Job Satisfaction (PA) & Low & $115(44.23)$ \\
& High & $111(42.69)$ \\
& Moderate & $60(23.08)$ \\
& Low & $89(34.23)$ \\
\hline
\end{tabular}

EE: Emotional exhaustion, DP: Depersonalization, PA: Personal achievement

appear not all three subscales demands should be fulfilled, therefore the largest percentage of the examinees has high risk presented in the results of at least one subscale. The most frequent factors combinations leading to burnout are from subscales EE and DP (26). The previously showed results have also been showed in Schaufeli et al. study (27), therefore EE and DP subscales are considered to be the best indicators of the level of work burnout.

\section{CONCLUSION}

This study focused on detection of burnout syndrome among banking employees. Job burnout dosen't appear suddenly. For controlling and avoiding job, burnout focusing on warning factors is so much important which the employees should be aware about them. These factors included various beneficial programs for improving physical status (exercise, meditation, etc.) Using relaxing methods also help to be patient and calm in inconvenient situation. In addition, the employees can take part in some educational workshops and seminars to learning different organization behavior, methods, and strategies that can be beneficial for workplace and them. We found a lack of research on burnout in bank employees in Bosnia and Herzegovina, indicating the need for further studies in this population group. Subjects of both genders are emotionally exhausted, with DP prevailing with male employees. There is direct correlation between working years in banking sector and number of working hours with burnout syndrome. Work-related stress can be prevented by investing in employee education, by encouraging the participation of employees in the decision-making process, as well as by investing in the quality of the work environment.

\section{Limitations of the Study}

There were several limitations in conducting this study. First, the results could be biased because this is self-reported questionnaire. Secondly, since this research was based on a cross-sectional study, it was not possible to examine a possible cause-and-effect relationship. We did not ask about the number of traumatic experiences that participants had experienced either at their workplace or in their home life and we did not consider family situations, except for sociodemographic factors.

Participation of the banking sector employees is voluntarily, and therefore one can inadvertently dismiss the opinion of those who do not agree to participate which could lead 
to biased information. However, for this study, we have contancted top management through human resources department explaining its advantages for the employees which should motivate them enough to participate. Thirdly, methodological limitation is that the sample is not homogeneous because there are many more woman than men in sample. Why is this important? It is necessary to create different policies in the general working surrounding, as well as create plan in securing mental health of the banking sector employees.

\section{DECLARATION OF INTERESTS}

The authors declare no conflict of interest.

\section{REFERENCES}

1. Giorgi G, Arcangeli G, Perminiene M, Lorini C, Ariza-Montes A, Fiz-Perez J, et al. Work-related stress in the banking sector: A review of incidence, correlated factors, and major consequences. Front Psychol 2017;8:2166.

https://doi.org/10.3389/fpsyg.2017.02166

2. Mannocci A, Marchini L, Scognamiglio A, Sinopoli A, De Sio S, Sernia S, et al. Are bank employees stressed? Job perception and positivity in the banking sector: An italian observational study. Int J Environ Res Public Health 2018;15(4):E707. https://doi.org/10.3390/ijerph15040707

3. Silva JL, Navarro VL. Work organization and the health of bank employees. Rev Lat Am Enfermagem 2012;20(2):226-34 https://doi.org/10.1590/s0104-11692012000200003

4. Li X, Kan D, Liu L, Shi M, Wang Y, Yang X, et al. The mediating role of psychological capital on the association between occupational stress and job burnout among bank employees in China. Int J Environ Res Public Health 2015;12(3):2984-3001. https://doi.org/10.3390/ijerph120302984

5. Chigerwe M, Boudreaux KA, Ilkiw JE. Assessment of burnout in veterinary medical students using the Maslach burnout inventory-educational survey: A survey during two semesters. BMC Med Educ 2014;14:255. https://doi.org/10.1186/s12909-014-0255-4

6. Leka S, Griffiths A, Cox T. Protecting Workers' Health Series No. 3. Work Organization and Stress. Geneva, Switzerland: WHO; 2005.

7. de Beer LT, Schaufeli WB, De Witte H, Hakanen JJ, Shimazu A, Glaser J, et al. Measurement invariance of the burnout assessment tool (BAT) across seven cross-national representative samples. Int J Environ Res Public Health 2020;17(15):E5604. https://doi.org/10.3390/ijerph17155604

8. Marić N, Mandić-Rajčević S, Maksimović N, Bulat P. Factors associated with burnout syndrome in primary and secondary school teachers in the republic of Srpska (Bosnia And Herzegovina). Int J Environ Res Public Health 2020;17(10):E3595. https://doi.org/10.3390/ijerph17103595

9. Khalid A, Pan F, Li P, Wang W, Ghaffari AS. The impact of occupational stress on job burnout among bank employees in Pakistan, with psychological capital as a mediator. Front Public Health 2019;7:410.

https://doi.org/10.3389/fpubh.2019.00410

10. Giorgi G, Arcangeli G, Ariza-Montes A, Rapisarda V, Mucci N. Work-related stress in the Italian banking population and its association with recovery experience. Int $J$ Occup Med Environ Health 2019;32(2):255-65. https://doi.org/10.13075/ijomeh.1896.01333

11. Kumar SG, Unnikrishnan B, Nagaraj K. Self-reported chronic diseases and occupational health risks among bank employees of southern Karnataka city, India. Indian J Community Med 2013;38(1):61-2.

https://doi.org/10.4103/0970-0218.106633

12. Salvagioni DA, Melanda FN, Mesas AE, González AD, Gabani FL, Andrade SM. Physical, psychological and occupational consequences of job burnout: A systematic review of prospective studies. PLoS One 2017;12(10):e0185781.

https://doi.org/10.1371/journal.pone.0185781

13. Thorsen VC, Tharp AL, Meguid T. High rates of burnout among maternal health staff at a referral hospital in Malawi: A cross-sectional study. BMC Nurs 2011;10:9. https://doi.org/10.1186/1472-6955-10-9

14. Grattan RD and Ladyman RS. Neurophysiological and cognitive changes in pregnancy handbook of clinical neurology. In: Steegers EA, Cipolla MJ, Miller EC, editors. Neurology and Pregnancy: Pathophysiology and Patient Care. Vol. 171. Amsterdam, Netherlands: Elsevier; 2020.

15. IBM Corp. Released 2016. IBM SPSS Statistics for Windows, Version 24.0. Armonk, NY: IBM Corp; 2016

16. Cortina JM. What is coefficient alpha? An examination of theory and applications. J Appl Psychol 1993;78(1):98.

17. Purvanova RK, Muros JP. Gender differences in burnout: A meta-analysis. J Vocat Behav 2010;77:168-85.

18. Horvat $\mathrm{G}$, Tomašević $\mathrm{S}$, Leutar $Z$. Sindrom sagorijevanja na poslu djelatnika bankarskog sektora koji su u direktnom kontaktu s korisnicima. Soc Teme 2016;1(3):31-47.

19. Cakınberk A. Studying the relationship between employees' occupational burnout levels and satisfaction of life: A research in private banks. Afr J Bus Manage 2011;5(16):6825-38

20. Gidou M, Paltayian G, Gavalas D. Job burnout and job satisfaction in the banking sector; the perceptions of bank employees in Greece. Rev Econ Finance 2020;18:13-8.

21. Al-Kahtani NS, Allam Z. A comparative study of job burnout, job involvement, locus of control and job satisfaction among banking employees of kingdom of Saudi Arabia. Life Sci J 2013;10(4):2135-44.

22. Stanketic KD, Savic SM, Racic M. The prevalence of stress and burnout syndrome in hospital doctors and family physicians. Med Pregl 2016;69(11-12):356-65. https://doi.org/10.2298/mpns1612356s

23. Hino A, Inoue A, Mafune $K$, Hiro $H$. The effect of changes in overtime work hours on depressive symptoms among Japanese white-collar workers: A 2-year follow-up study. J Occup Health 2019;61(4):320-7. https://doi.org/10.1002/1348-9585.12054

24. Chen Y, Li P, Yang C. Examining the effects of overtime work on subjective social status and social inclusion in the Chinese context. Int J Environ Res Public Health 2020;17(9):E3265.

https://doi.org/10.3390/ijerph17093265

25. Amigo I, Asensio E, Menéndez I, Redondo S, Ledesma JA. Working in direct contact with the public as a predictor of burnout in the banking sector. Psicothema 2014;26(2):222-6.

https://doi.org/10.7334/psicothema2013.282

26. Vinnikov D, Tulekov Z, Akylzhanov A, Romanova Z, Dushpanova A, Kalmatayeva Z Age and work duration do not predict burnout in firefighters. BMC Public Health 2019;19(1):308

https://doi.org/10.1186/s12889-019-6643-2

27. Schaufeli WB, Bakker AB, Hoogduin K, Schaap C, Kladler A. On the clinical validity of the maslach burnout inventory and the burnout measure. Psychol Health 2001;16(5):565-82.

https://doi.org/10.1080/08870440108405527

\section{RELATED ARTICLES PUBLISHED IN JHSCI}

1. Bošković S. Structure and psychometric properties of the maslach burnout inventory in Croatian nurses. JHSCl. 2021;11(1):25-8.

2. Sadiković A, Kurtić A, Sadiković O, Mulić M, Džubur- Alić A, Smajović M, Pašalić A. Road to healthcare professional's burnout: poor empathy and impaired work ability, are they cause or effect?. JHSCl. 2019;9(2):99-107.

3. Džubur A, Lisica D, Abdulahović D, Avdić D, Smajović M, Mulić M. Burnout syndrome in primary healthcare professionals. JHSCl. 2018;8(2):122-7.

4. Obradović Z, Obradović A, Ćesir Škoro I. Nurses and burnout syndrome. JHSCI. 2013;3(1):60-4. 